Cuadernos de Filología Clásica. Estudios Latinos

ISSN: 1131-9062

https://dx.doi.org/10.5209/cfcl.67102

\title{
La traducción de Lucrecio del presbítero Matías Sánchez (ms. II 646 de la Biblioteca del Palacio Real)
}

\author{
Ángel Jacinto Traver Vera ${ }^{1}$
}

Recibido: 7/5/2019 / Aceptado: 29/11/2019

Resumen. Este artículo estudia el MS II 646 de la Biblioteca del Palacio Real de Madrid, debido al presbítero Matías Sánchez, quien vertió en verso el De rerum natura de Tito Lucrecio el año 1832. El manuscrito contiene, como se ha puesto de manifiesto recientemente, la misma traducción que la del ms. 287, conservado en la Biblioteca Menéndez Pelayo de Santander. Este último supuestamente ha preservado la traducción del abate Marchena, hecha cuarenta y un años antes (1791). Tras hacer una pequeña collatio de estos dos manuscritos, la conclusión más plausible es que el sacerdote Matías Sánchez fuera el verdadero autor de la traducción y no el "abate Marchena".

Palabras clave: MS. II 646; MS. 287; Matías Sánchez; José Marchena; Lucrecio.

\section{The translation of Lucretius by the presbyter Matías Sánchez (MS II 646 of the Royal Palace Library)}

\begin{abstract}
This paper studies the manuscript II 646 of the Royal Palace Library of Madrid. Its author, the priest Matías Sánchez, translated into verse the De rerum natura of the Latin poet Lucretius in 1832. As it has been recently announced, this manuscript contains the same translation than the manuscript 287, conserved in the Menéndez Pelayo Library of Santander. This last one has supposedly preserved the translation by the "Abbot Marchena", made forty one years before (1791). After having done a small collatio of these two manuscripts, the more plausible conclusion is that the priest Matías Sánchez was the true author of this translation and not the "Abbot Marchena".
\end{abstract}

Keywords: MS. II 646; MS. 287; Matías Sánchez; José Marchena; Lucretius.

Sumario. 1. Introducción. 2. El informe de la Academia Greco-Latina. 3. La compra del MS por la Biblioteca del Palacio Real (1871). 4. El texto de los mss. II 646 y 287 y la edición de Menéndez Pelayo (1896): variantes, lagunas y modificaciones. 5. Conclusiones. 6. Referencias bibliográficas.

Cómo citar: Traver Vera, A. J. La traducción de Lucrecio del presbítero Matías Sánchez (ms. II 646 de la Biblioteca del Palacio Real), en Cuad. Filol. Clás. Estud. Lat. 39 (2) (2019), 291-312.

1 IES San Fernando (Badajoz). Correo electrónico: veratraver@gmail.com 


\section{Introducción ${ }^{2}$}

La traducción de Lucrecio parece coronar la vida y obra del "abate Marchena" (1768-1821), la de un intelectual ilustrado, afrancesado y heterodoxo que pasó de estudiar para sacerdote a ser perseguido por el Santo Oficio, justo cuando estallaba la Revolución Francesa que él abrazó jubilosamente. Cuando Marcelino Menéndez Pelayo (1856-1912) recibió en torno a 1875 como regalo el ms. 287 (Biblioteca Menéndez Pelayo de Santander) de manos de su amigo y pariente Damián Menéndez Rayón, que causalmente lo había encontrado en un puesto de libros, dudó en asignar la versión castellana a Marchena al ver las iniciales del colofón, pues estas no se correspondían con las que él entonces conocía. La R de "Ruiz" le desconcertaba. Al descubrir, en torno a enero de 1876, el nombre completo, "José Marchena Ruiz de Cueto", el ligero desorden de las siglas no fue óbice para que presumiera la autoría de Marchena ${ }^{3}$.

Tras comentárselo a Menéndez Rayón por carta, este le respondió (Madrid, 10 de febrero de 1876) aplaudiendo sus desvelos y refiriendo datos fundamentales sobre el hallazgo del ms. 287 de esta guisa (Revuelta Sañudo 2008, I 302):

La noticia que me dá V. del incógnito traductor de Lucrecio me ha sorprendido sobre manera, puesto que esta rodeada de una muy fuerte verosimilitud. La noticia me llenó de gozo y aplaudo su actividad y desvelos sobre este asunto. La copia es posible se haya hecho en Valmojado ó también que él lo haya puesto en limpio en aquel punto, y que posteriormente haya caido en manos de un curioso que sacó la copia ad litteram salvo aquel añadido de finis in totum que tanto le sorprendió á $\mathrm{V}^{4}$. - De todos modos creo que la copia se ha hecho en Madrid por algun escribiente á quien se le mandó hacerla. Tengo dos razones para creerlo; la primera, que es letra muy tendida y suelta, cosa poco comun en los escritores. La segunda, la clase de tinta, igual á la muchedumbre de escritos que diariamente estoy viendo aqui. Yo creo que este escrito se ha hecho aqui y debió hacerse del 30 al 40, poco mas o menos, por el original; primero porque la letra tomó ese caracter oficinesco por ese tiempo y segundo porque cuando lo compré tenia muchos polvos pegados á las letras, lo cual en un libro usado no es fácil, y tercero porque recuerdo que cuando lo adquirí era la encuadernación bastante reciente. Lo que habria que averiguar era donde para

2 Agradezco a Gabriel Laguna Mariscal, director de mi tesis Lucrecio en España (Cáceres, 2009), la información sobre el artículo de Pablo Asencio (2013); a Francisco García Jurado, el habérmelo facilitado; a José-Ignacio García Armendáriz, la noticia de la existencia del ms. II 646, y a los bibliotecarios de la Biblioteca del Palacio Real y de la Biblioteca Menéndez Pelayo, su inestimable colaboración. Por último, quisiera dar las gracias a los revisores del bosquejo de este artículo por sus atinadas sugerencias y observaciones.

He usado el siguiente material original: copia digital en color del ms. II 646, del certificado de D. José Cambronero adjunto en el mismo y de los borradores de oficio y oficio para la adquisición del ms. II 646. Del ms. 287 he cotejado veinte caras de folios en copia digital en blanco y negro (portada, colofón, ff. 9 v.-10 r., 43 v.- 45 r., 72 v.-74 r., 103 v.-104 r., 111 v.-112 v., 190 v.-191 r., 167 v.-168 r., 206 v.-207r. y 256 v.-258 r.). En su día, adquirí aproximadamente la mitad de estas copias para la realización de mi tesis, el resto las he solicitado para este artículo. Por fortuna, la oficina de reproducción pudo facilitármelas a partir de un microfilm antes de que suspendiera su servicio, pues la Biblioteca Menéndez Pelayo está siendo reformada.

3 Sus dudas sobre la interpretación de las siglas están recogidas en dos cartas (I 212 y 290, de 1875 y 1876 respectivamente) dirigidas a Gumersindo Laverde, quien le responde (I 291, de 1876) secundando la conjetura de que sea Marchena el traductor (Revuelta 2008). En este epistolario (I 165, de 1875), se alude también al ms. 287 , que, al parecer, el propio Menéndez Rayón tenía intención de publicar, y al orden de las iniciales “J. R. M. C.”.

4 Solía ser Finis o Finis. Laus Deo. Cf. Artigas y Sánchez Reyes (1957, 30, nº 17; 225, nº 112, ó 315, n 183, 20). 
el original, y si yo tuviera tiempo daria algunos pasos en este sentido; pero lo que importa y V. ha conseguido, como creo, es saber el autor que puede poner en camino de averiguar lo que resta.

Esta información de Menéndez Rayón, archivero del Ministerio de Hacienda en Madrid (Canella Secádes 1903-1904, 763), no era baladí, ni tampoco el trastorno de las iniciales. Todos eran datos suficientemente relevantes como para que el erudito santanderino los hubiera incluido en su magno estudio sobre Marchena (1896) ${ }^{5}$. En su lugar, hizo una síntesis y dio a entender que las cuatro iniciales de la subscripción respetaban el orden del nombre completo de Marchena (Menéndez Pelayo 1896, XI):

El manuscrito no parece original, sinó copia de amanuense descuidado, aunque no del todo imperito. No tiene expreso el nombre del traductor, pero sí sus cuatro iniciales J. M. R. C., y al fin la fecha de 1791, sin prólogo, advertencia ni nota alguna.

Con esta afirmación ${ }^{6}$ las dudas sobre la autoría de Marchena se desvanecieron entre los críticos y el gran público que desconocían los detalles. Si acaso, tan solo causaba entre los estudiosos de Marchena cierta incertidumbre el hecho de que existiera un único manuscrito y en posesión de Menéndez Pelayo ${ }^{7}$.

En mi tesis, Lucrecio en España, estudié (2009, 567-75) otra versión castellana del De rerum natura: el ms. II 646 (Biblioteca del Palacio Real de Madrid), de 1832 y debida a Matías Sánchez, miembro de la Academia Greco-Latina. Supe de su existencia gracias al profesor José-Ignacio García Armendáriz, quien conocía el dato por una mención, bastante escondida, de Gutiérrez del Caño (1992 II, 226). Tuve la suerte de hallar entre sus hojas de guarda un informe de la Academia Greco-Latina denegando su publicación, que estimé de gran importancia para la tradición clásica de Lucrecio en España, y apunté, como hipótesis, que Matías Sánchez hubiera sido un religioso reformista.

Posteriormente, Pablo Asencio (2013, 419-22) removió de nuevo aquellas dudas que cavilaba el erudito santanderino en su epistolario, al sostener en su artículo que probablemente la traducción en endecasílabos sueltos del ms. 287, atribuida por Menéndez Pelayo a José Marchena, no era suya en realidad, pues las iniciales de la subscripción del traductor, «J. R. M. C.», no coincidían al cien por cien con el nombre de José Marchena Ruiz de Cueto.

Y recientemente Molina Sánchez (2018, 349-52), al descubrir que la traducción lucreciana de Matías Sánchez es básicamente la misma que la del ms. 287, ha hecho una aportación muy valiosa para el esclarecimiento del verdadero autor de esta versión, que ha sido la más popular y editada en España. En su artículo, el profesor Molina Sánchez $(2018,348-49)$ daba poca credibilidad a mi conjetura $(2009,572$,

5 Hubiera sido conveniente saber, por ejemplo, si en traducciones o ensayos polémicos era más o menos habitual el cambio de siglas como procedimiento de ocultación. El orden correcto de las iniciales está registrado también en el catálogo de manuscritos de Artigas y Sánchez Reyes (1957, 101, n 59): «(fol. 260 v.) A. ... antes que los cadáveres soltasen. Finis in totum | et |Canticorum. | Año de 1791, en Valmojado | por Dn. J. R. M. C.». Ya había afirmado esto mismo (Menéndez Pelayo 1881 III, 370) en su Historia de los heterodoxos españoles. Una década más tarde Blanco García (1891 I, 40-41) en su Historia de la Literatura Española en el siglo XIX ya se hacía eco de esta traducción, sin dudar de la autoría de Marchena. Alude allí al único manuscrito en posesión de Menéndez Pelayo. 
n. 268) de que Matías Sánchez hubiera sido religioso y, más concretamente, jesuita progresista. Sin embargo, fue presbítero según he podido comprobar a posteriori ${ }^{8}$. Y este dato aporta una nueva perspectiva, máxime cuando sabemos sin lugar a dudas que ambos manuscritos han transmitido la misma traducción, y cuando hay, en mi opinión, motivos textuales y documentales suficientes para pensar que fue Matías Sánchez el verdadero autor de la traducción.

Cuando Marcelino Menéndez Pelayo publicó, con bastantes enmiendas de su musa, la supuesta versión del joven revolucionario en 1896, desconocía la existencia de este ms. de Matías Sánchez . Y el suyo solo contenía el texto, «sin prólogo, advertencia ni nota alguna» (Menéndez Pelayo 1896, XI); pero el ms. II 646 de este sacerdote y miembro de la Real Academia Greco-Latina, sí tiene advertencia, notas al comienzo y comentarios al final de cada uno de los seis libros lucrecianos. Y, como se extrae de su texto, es más fiel y completa traducción que la del ms. 287. La interrogación que inmediatamente se suscita es ¿por qué un religioso en aquellos convulsos años quiso romancear al impío Lucrecio en España, bastión del catolicismo, o, aún peor, dar por suya la versión del De rerum natura debida al "abate Marchena"?

Aunque a primera instancia pueda parecernos sorprendente, muchas de las traducciones lucrecianas fueron hechas por doctos religiosos ${ }^{10}$. Es más, la propia pervivencia de los códices del De rerum natura es prueba de que, pese a agrias polémicas, presiones y disputas, prevaleció el sentido común en el seno de la Iglesia. Tuvieron ocasión, si hubieran querido, de haberlos hecho desaparecer para siempre, pero los conservaron para la posteridad. En la tradición ortodoxa, sin embargo, ni se ha conservado el apóstol, Lucrecio, ni el maestro, Epicuro, más esperable por haber escrito en griego (Flores 1980, 64). En este sentido, encuentro palabras muy iluminadoras en el siguiente texto del jesuita José Mendive (1887, 412-13):

Lucrecio, contemporáneo de Cicerón, compuso un largo poema en seis libros para explicar esta misma procedencia, siguiendo las huellas de Epicuro, Empédocles y Demócrito; obra que, á pesar de toda su impiedad y descarado ateísmo, ha podido llegar hasta nosotros merced á la diligencia y cuidado de aquellos monjes de la Edad Media que ahora se ven pintados por los materialistas y ateos de nuestra épo-

8 Su condición de sacerdote aparece en varias ediciones de la Guía de litigantes y pretendientes de la Corte de Madrid. Entre los listados de cargos, miembros numerarios y supernumerarios de la Academia Greco-Latina que este vademécum ofrece, está citado así: «Sr. D. Matías Sánchez, presbitero» ( $c f$., entre otros, Nifo 1835, 112, y 1838, 69).

9 Dice Menéndez Pelayo (1896, XVI, n. 1): «El MS. de mi biblioteca (único que conozco) me fue regalado por mi difunto amigo D. Damián Menéndez Rayón, que le había encontrado casualmente en un puesto de libros. Con intento de remediar algunos de los innumerables lunares de estilo y versificación que le afean, he hecho en él algunas correcciones al imprimirle». En carta a Gumersindo Laverde (Revuelta Sañudo 2008, I 198), afirma: «De Lucrecio llevo revisados los tres primeros libros, ó sea la mitad del poema. He tenido que hacer cerca de 500 enmiendas, más o ménos importantes» ( $c f$. también la carta I 210).

10 Quizás las más significativas para este caso resulten las del abad de Villeloin, Michel de Marolles (1600-1681), quien estudió un tiempo con los jesuitas y tradujo el poema latino al francés por primera vez en 1650 (Traver 2009, 439): Le poete / Lucrece / latin et françois, / De la Traduccion de M. D. M., A Paris, Chez Toussainct Quinet, au Palais, sous la montée de la Cour des Aydes (BN 4/200319); y la del también antiguo jesuita y "abate", esta vez italiano, Raffaele Pastore (n. 1732): La filosofia della natura di Tito Lucrezio Caro: e confutazione del suo deismo e materialismo, vols. I-II, Londra, 1776 (Prosperi 2005, 423-26). Aunque no lo tradujo, merece citarse, por su transcendencia, al insigne teólogo y científico Pierre Gassendi (1592-1655), conciliador del atomismo antiguo y la doctrina cristiana (Traver 2009, 391-97), cuyas obras dedicadas a Epicuro crearon el clima propicio en Francia para traducir a Lucrecio (Norbrook 2016, 20). 
ca con los negros colores del oscurantismo, cual si hubieran tratado de hundir en el polvo para siempre las riquezas artísticas de la civilización antigua, ó de ocultar cautelosamente, los irrefragables argumentos que aquellos sabios paganos idearon en favor de su irreligiosa filosofía.

¡Cosa admirable! Todo cuanto ahora nos venden como nuevo y reciente los proclamadores de la evolución materialista, ya lo hallamos descrito por este famoso poeta romano, quien nos dice haberlo copiado de los filósofos sobredichos. Hasta la misma selección natural imaginada por Darwin, se encuentra ya allí profesada por Lucrecio en el libro I de su poema ${ }^{11}$.

\section{El informe de la Academia Greco-Latina}

Como advierte en su artículo Molina Sánchez (2018, 349), es, cuando menos, asombroso que ningún miembro de la Academia Greco-Latina matritense se percatara de que la versión que D. Matías Sánchez quería dar a los tórculos en 1832 era la misma que había hecho clandestinamente algo más de cuarenta años antes (1791) D. José Marchena, muerto no mucho tiempo atrás en la villa y corte de Madrid (31 de enero de 1821$)^{12}$. En aquel mundo conflictivo, de tertulias, rumores, comidillas y manuscritos prohibidos, donde la información era bien preciado, nadie identificó el plagio, ni siquiera los miembros que en el seno de la Real Academia hubieron de discutir la conveniencia o no de imprimir la traducción.

Por entonces, la Greco-Latina estaba inmersa en un magno proyecto de modernización de los estudios clásicos en España, dentro del cual destacaba la publicación en castellano de obras emblemáticas de los clásicos, de ahí que bajo su patronazgo se imprimieran traducciones de Homero, Virgilio, Horacio, Ovidio y otros ${ }^{13}$.

Tras el examen de la propuesta efectuada por el autor y legítimo miembro, D. Matías Sánchez, el secretario de la Academia Greco-Latina, D. José María Cambronero (1804-1841), emite el siguiente informe ${ }^{14}$ :

Don José Ma . Cambronero, Doctor en leyes por la R. Universidad de Alcalá de Henares, Abogado de los R. Consejos, y Secretario de la R. Academia Greco-Latina:

Certifico: Que habiéndose presentado à esta R. Academia por su digno individuo D. Matías Sánchez una traducción del Lucrecio, poeta latino, para que se imprimiese, la ha reconocido prolijamente y admirando el esmero con que está versifi-

11 El fragmento forma parte del capítulo "Doctrina del transformismo acerca del origen del hombre". Aunque Mendive (1836-1906) hace solo alusión al libro I, la preformulación lucreciana de esta teoría aparece por extenso en LuCR.5.772-1457.

12 Los últimos días y momentos de su muerte están relatados por Menéndez Pelayo (1896, CL-CLIII) y Fuentes (1989, 301-4).

13 Hualde Pascual y García Jurado (2004 y 2005) escribieron dos artículos fundamentales sobre la historia de la Academia Greco-Latina y su ambicioso programa renovador. Fundada en 1755, estuvo abierta hasta el año 1849. El periodo de mayor esplendor, 1831-1833, coincidió con los últimos años del rey absolutista Fernando VII. Fue precisamente entre estos años cuando Matías Sánchez presentó su versión. Sobre las traducciones lucrecianas en este período, $c f$. García Armendáriz (2002, 103-18).

14 Se ha conservado adjunto en el ms. II 646 de la Biblioteca del Palacio Real. Tomo la transcripción de Molina Sánchez $(2018,347-48)$. Tan solo cambio «verificada» por «versificada». 
cada por la inmensa dificultad que opone la irregularidad del testo y la oscuridad de algunos conceptos, por lo que no pudo menos de alabar la laboriosidad y diligencia del traductor; pero reflecsionando que si se publicase del modo literal con que ha sido concebida se haría demasiado vulgar, cayendo en manos inespertas y poco preparadas para resistir a los principios arriesgados que sienta el autor, acordó esta R. Academia que se devolviese la obra con este elogio y observaciones à quien la había presentado ya para su satisfacción, ya también para que hiciese de ella el uso más conveniente. Madrid veinte y nueve de Diciembre de mil ochocientos treinta y dos. José Ma . Cambronero.

José María Cambronero, abogado, diputado y gobernador en varias provincias ${ }^{15}$, era uno, pese a su juventud, del que cabía esperarse que supiera algo de la traducción de José Marchena, amén -claro está- de algún otro miembro, ya religioso o laico, de la sociedad grecolatina. Don José era familiar -seguramente primo- del afrancesado jurisconsulto Manuel $\mathrm{M}^{\mathrm{a}}$ Cambronero (1764-1834) ${ }^{16}$, quien ocupó el cargo de Consejero de Estado (Fuentes 1989, 301, n. 142) durante el corto reinado de José I (1808-1813) y fue conocido del "abate Marchena”, según se desprende de esta noticia recogida por Menéndez Pelayo (1896, CLII) en su biografía:

Pocos instantes antes del que fué su postrero (sc. día de Marchena) me llamó, y á presencia del general Quiroga, del Marqués de Almenara, de D. Manuel Cambronero y D. Ramón de Ceruti, me dijo: "Diga usted al folletista que ha pretendido infamarme, que si quiere vivir feliz aun en medio de las mayores desgracias, y descender á la tumba con la serenidad que yo desciendo, que aprenda á ser hombre de bien".

Aquella amistad seguramente venía de años atrás, al menos de cuando ambos se sumaron a la invasión napoleónica que traía los aires de la deseada modernización de España, anclada aún en el Antiguo Régimen. Y debieron de ser varios los momentos en que coincidieron, al ostentar los dos cargos en la alta administración bonapartista. De nuevo, Menéndez Pelayo (1896, XCIX-C, n. 2) aporta datos interesantes a este respecto $^{17}$ :

El intruso rey Bonaparte nombró á Marchena director (ó como entonces se decía redactor) de la Gaceta y archivero mayor del Ministerio del Interior (hoy de la Gobernación); incluyó su nombre en la lista de individuos que habían de formar parte de una grande Academia ó Instituto Nacional que pensaba fundar (2); [en nota]

15 Tomo algunos datos biográficos de la noticia de su fallecimiento aparecida en el periódico El Corresponsal $(1841,4)$ en la sección "Madrid 12 de Setiembre".

16 Ambos aparecen listados, uno tras otro, como abogados de los «Reales Consejos y M. I. Colegio de Madrid» en la Guía de Litigantes y pretendientes (Nifo 1828, 87, y 1830, 92). Recuerda López Tabar (2014, 79-108), al repasar la carrera y vida de Manuel $\mathrm{M}^{\mathrm{a}}$, que en su casa, tal como narra Pérez Galdós en Los apostólicos, se instaló una famosa tertulia donde acudieron, entre otros, Vega, Espronceda y el suicida Larra, quien conocería allí a Dolores Armijo, mujer del hijo de Manuel María, José María Cambronero, de mismo nombre que el secretario de la Academia Greco-Latina.

17 El erudito y polígrafo santanderino toma los datos, según avisa en la nota 2, de Manuel Dánvila y Collado, El poder civil en España, Madrid, Imprenta y Fundición de Manuel Tello, vol. VI, 1887 (¿1886?), p. 668. 
En este proyecto, que es muy curioso, figuran una porción de nombres verdaderamente ilustres [...] los médicos Luzuriaga, García Suelto, Rives y D. Eugenio de la Peña, el ideólogo Narganes de Posada, los jurisconsultos Cambronero, Arnao, y Sotelo [...] los helenistas Canseco, Hermosilla y Tomás y García [...] los humanistas Tineo, Melón, Cabrera, Estala y un D. Carlos Pignatelli á quien se califica de "literato muy instruido, que trabajaba en una traducción de Lucrecio celebrada por los conocedores..."

En aquellos días, en los que el utrerano Marchena no hubiera tenido empacho -ni riesgo a la vista había- de jactarse de su juvenil traducción de Lucrecio, prefirió guardar el secreto, como recuerda Pablo Asencio (2013, 421). Ningún comentario de su versión hizo a sus correligionarios y amigos, ni tampoco al émulo Pignatelli ${ }^{18}$. Ninguno de ellos - que sepamos- transmitió noticia alguna de su traducción. Resulta extraño, por no decir inverosímil.

Si la mención de «un Carlos Pignatelli» resulta ciertamente misteriosa, tras la retahíla de artículos determinados («los [...] el [...] los [...]»), no menos llega a ser la persona del presbítero D. Matías Sánchez, figura clave en este asunto. Todo sobre su vida, salvo cuatro datos, es silencio y conjetura ${ }^{19}$. Comparada con la de Francisco Lorente, también presbítero y miembro asimismo de la Academia Greco-Latina, citado en la Guía de litigantes y forasteros de 1835 (Nifo 1835, 112) tan solo un puesto por debajo de él en la relación de supernumerarios de la institución, la carrera de D. Matías resulta anodina ${ }^{20}$.

Pero Lorente no tradujo a Lucrecio. Matías Sánchez, sí, según se deduce de la documentación. Y aun en el supuesto de que hubiera sido un plagiario (Molina Sánchez 2018, 352), era manifiesta su voluntad de publicarlo, y este afán pudo truncar su carrera como prometedor latinista ${ }^{21}$. Según el informe de José María Cambronero,

18 Es posible que fuera el sobrino de San José Pignatelli de Aragón y Moncayo (1737-1801), héroe jesuita y hermano menor de Joaquín Atanasio Pignatelli (1724-1776), Conde de Fuentes y embajador de Carlos III en Turín, Londres y París. Este último tuvo catorce hijos con Doña María Luisa Gonzaga y Caracciolo, siendo el último Carlos Pignatelli de Aragón y Gonzaga, nacido en París en 1766 y bautizado solemnemente en el Real Sitio del El Pardo el 17 de marzo de 1773. Fue Caballero Guardia Marina, «en cuya Real Compañía de Cádiz ingresó el 12 de junio de 1786» (Gómez de Olea y Moreno Mayerhoff 2007, 224). Cf. también Forcada Torres (1966, 149-51, n. 8). Su empeño demuestra de nuevo que Lucrecio fue un autor muy del gusto de los revolucionarios franceses y, como vemos, también españoles (Traver 2009, 493).

19 No debe confundirse con el Padre Matías Sánchez (1697 - ca. 1757), jesuita, autor de El padre de familias brevemente instruido en sus muchas obligaciones de padre, obra edificante reimpresa en numerosas ocasiones, cuya editio princeps data posiblemente de 1792 (en la imprenta de D. Joseph Doblado, BN 3/48629). Sobre este autor, $c f$. Aguilar Piñal (1993, 478-79).

20 Dice así una semblanza moderna de Francisco Lorente hecha por Ramos Santana (2002, 121): «Francisco Lorente, de origen aragonés, fue presbítero y canónigo de Valladolid, además de catedrático de teología del Seminario Conciliar de Segorbe y miembro supernumerario de la Real Academia greco-latina. En 1834 publica en Madrid, en la imprenta de la calle del Amor de Dios n 14, Las Bucólicas de Virgilio, traducidas en verso castellano con algunas notas, por el Presbitero Don Francisco Lorente. También tradujo algunos fragmentos de la Eneida y de las Geórgicas (Madrid, 1856) y Los Cánticos de Salomón (Valencia, 1822). Compuso además un Discurso con el motivo de haber jurado el Rey la Constitución Política de la Monarquía Española, que se pronunció en la catedral de Jaca y se publicó en Zaragoza en 1820, así como un Compendio de la historia de la aparición y milagros de Nuestra Señora del Tremendal (Zaragoza, 1858 y 1866)».

21 Basta con leer las notas y comentarios a los libros lucrecianos del ms. II 646 para percatarse de su sólida formación latina y filosófica. Entre los autores latinos que cita y en ocasiones traduce, se cuentan Virgilio, Horacio, Ovidio, Séneca, Manilio, Lucano y Petronio, entre otros. Michel de Marolles, que sí imprimió su traducción con el privilegio de la realeza francesa, tuvo una carrera brillante; si no igual, sí algo similar hubiéramos esperado 
recogió la versión del De rerum natura con un elogio «para su satisfacción» y con la advertencia de que «hiciese de ella el uso más conveniente», a sabiendas de que si caía en manos pocos expertas podría difundir tesis heréticas entre la plebs infima ${ }^{22}$. Si consideramos los ataques y dificultades que sufrieron algunas traducciones del $D e$ rerum natura y sus autores, como el abate de Villeloin, Michel de Marolles (1650), en Francia, y Alexandro Marchetti (1669) y el abate Raffaele Pastore (1776) en Ita$\operatorname{lia}^{23}$, por traer una muestra debida a católicos, la de Matías Sánchez debió de levantar también ampollas, aunque fuera en petit comité.

\section{La compra del ms. II 646 por la Biblioteca Real de Palacio (1871)}

Como quiera que fuese, la siguiente noticia sobre su traducción en endecasílabos sueltos, aparece en el borrador de oficio ${ }^{24}$ que don Manuel Carnicero dirige al Mayordomo Mayor interino del Palacio Real, don José Rossell, el 29 de agosto de 1871, pocos años antes de que Damián Menéndez Rayón adquiriese, posiblemente en 1874, otra copia en un puesto de libros antiguos (Artigas y Sánchez Reyes 1957, 101). Dice así el borrador ${ }^{25}$ :

\section{Esteban Espinosa de los Monteros (D. Manuel) ${ }^{26}$}

En 22 de Agosto de 1871, presentó a S. M. una exposicion suplicandole se dignase ordenar la adquisición de una traducción inédita del Lucrecio.

En 29 de dicho mes y año se ordeno el presente informe.

En esta Biblioteca particular de S. M. existen cinco ediciones latinas del poema de Tito Lucrecio Caro, intitulado De rerum natura. Las cinco ediciones son diferentes, y dos de ellas notables:

Éstas son, las de los Aldos, y la que pertenece á la coleccion Bipontina. Tambien existen cuatro traducciones de dicho Poema: una francesa, y en prosa;

para Matías Sánchez. Según Gordon (1985, 151), destacan de Marolles las traducciones de varios poetas latinos (Terencio y Estacio, entre ellos), de varios libros de la Biblia (El cantar de los cantares, Los salmos y el Nuevo Testamento) y de un breviario para semana santa: L'Office de la Semaine Sainte, selon le Missel \& le Breviaire Romain. Avec la Concordance du Missel \& du Breviaire de Paris, A Paris, Par la Compagnie des Libraires associez, 1671.

22 Esta es la expresión que los inquisidores usaron en la censura que elevaron a la Congregación del Santo Oficio contra la publicación de la traducción italiana de Marchetti (Costa 2012, 87). Según un dato traído por Gordon $(1985,196)$ en su seminal estudio, la Iglesia Romana prohibiría la traducción italiana de Marchetti aduciendo las «confessions of several brothers named Legni that they had become atheists soley through reading Lucretius in Marchetti's translation».

23 Sobre las vicisitudes, prohibiciones, censuras y escándalos que provocaron, han escrito Gordon $(1985,151)$ y Costa (2012, 58-65 y 83-4) de Marolles; y Saccenti (1966) y Prosperi (2005) de Marchetti y Pastore respectivamente. El propio Marolles $(1656,187)$ reconoce en sus memorias que corrigió para su segunda edición la traducción del tercer libro: «à cause de la doctrine de ce Poëte dans son troisiesme Volume, où il traite de la Nature del'Ame».

24 Conservado en la Biblioteca del Palacio Real con la signatura ARB/10, CARP/4, doc. 197.

25 Pongo en cursiva las letras de las que tengo dudas.

26 Encuentro esta noticia suya en el periódico La correspondencia de España $(1871,3)$, aparecida poco después de su súplica: «D. Manuel Esteban y Espinosa de los Monteros, auxiliar del ministerio de la Gobernación, ha sido destinado al de Ultramar de oficial primero de administración». 
otra inglesa y en verso; y dos italianas y en verso, por Marchetti ${ }^{27}$; pero en el idioma castellano, ni en prosa ni en verso existe ninguna.

La traduccion inédita á que se refiere la presente exposición esta completa, y relativamente á su merito me abstengo de dar dictamen, después de haberla examinado, porque me parece muy respetable el del ilustre D. José $\mathrm{M}^{\mathrm{a}}$ Cambronero, que en forma de certificado, figura á la portada del libro, alentando á su lectura, á los que por ignorar quien pudiera ser el autor de la versión en verso suelto endecasílabo castellano, pudieran detenerse recelosos, antes de emprender la lectura de respetable número de páginas manuscritas.

Tengo el honor, devolver á VS. el volumen á que acabo de referirme y VS. con su mayor ilustración, se sirvirá resolver, no obstante lo expuesto, lo considere más conveniente.

Según este borrador, el ms. que tenían intención de adquirir era el mismo que el secretario D. José María Cambronero devolvió al presbítero Matías Sánchez con el informe incluido ${ }^{28}$. No se nos escapa que lo dicho al final no refleja bien el sentido del informe del secretario de la Academia, pues claro está que esta quería frenar su difusión:

reflecsionando que si se publicase del modo literal con que ha sido concebida se haría demasiado vulgar, cayendo en manos inespertas y poco preparadas para resistir a los principios arriesgados que sienta el autor, acordó esta R. Academia que se devolviese...

Sin embargo, el informe para su adquisición viene a decir lo contrario:

me parece muy respetable el (sc. dictamen) del ilustre D. José $\mathrm{M}^{\mathrm{a}}$ Cambronero, que en forma de certificado, figura á la portada del libro, alentando á su lectura, á los que por ignorar quien pudiera ser el autor de la versión en verso suelto endecasílabo castellano, pudieran detenerse recelosos, antes de emprender la lectura de respetable número de páginas manuscritas.

El ms. fue tasado en ciento cincuenta pesetas, cantidad que creían saciaba las expectativas del anónimo vendedor, como avisa el segundo borrador (ARB/10, CARP/4, doc. 198) de Manuel Carnicero a José Rossell:

27 Según este orden de citación son Andrea Navagero, Lucretius. Aldus, Venecia, 1515 (Gordon 1985, 53-55, $\mathrm{n}^{\circ}$. ref. 6. Signatura DIG/IX/4924_B); Titi Lucretii Cari de rerum natura libri sex, Biponti, Ex Typographia Societatis, 1782 (Gordon 1985, 98-99, nº. ref. 112. Signatura PAS/ARM4/318); Michel de Marolles, Les six livres de Lucrece de la nature des choses, A Paris: Chez Guillaume de Luyne (Gordon 1985, 155, nº. ref. 301 . Signatura VIII/3048); posiblemente Of the nature of things in six books: ilustrated with proper and useful notes, London, printed for Daniel Browne, at the Black Swan without Temple-bar, 1743 (Gordon 1985, 242-43, $\mathrm{n}^{\circ}$ 502B. Signatura IX/3841-IX/3842), y Alessandro Marchetti, Di Tito Lucrezio Caro della natura delle cose libri sei, In Amsterdamo a Spese dell' Editore T ${ }^{\circ} . \mathrm{P}^{\mathrm{o}}$., 1754 (Gordon 1985, 203, nº. ref. 381d. Signaturas XIV/375 y XIV/376).

28 Recordemos que en el informe el secretario dice literalmente «se devolviese la obra con este elogio y observaciones». 
Siendo esta la unica traduccion en castellano de que yo tenga noticia, del poema de Tito Lucrecio Caro y reuniendo las circunstancias q de anteriormente hablo, creo que, en una unión con el interesado puede justipreciarse en la cantidad de ciento cincuenta pesetas, no obstante, lo q VS. con su ilustrado criterio se digne resolver. Madrid 7 de octubre de 1871.

Finalmente, con la anuencia del rey Amadeo I se compró por ese precio, según el oficio definitivo (ARB/10, CARP/4, doc. 203) de José Rossell a Manuel Carnicero:

En virtud de los solicitado con fecha 22 de Agosto último por D. Manuel Esteban y Espinosa de los Monteros, y de conformidad con la opinion emitida por V. en 29 del mismo, S. M. el Rey (q. D. g) ha tenido á bien disponer que por esa Biblioteca se adquiera en el prefijado precio de ciento cincuenta pesetas el libro intitulado "Lucrecio" sobre la naturaleza de las cosas, traducido al castellano por M. S. P.

De orden de su S. M. lo comunico a V. para su conocimiento y efectos consiguientes.

guarde á V. muchos años

Madrid 27 de Octe. De 1871.

El Mayordomo Mayor interino

En la ficha catalográfica de los mss. existentes en la Biblioteca del Palacio Real, Andrés Escapa (1994) describe así el ms.:

Lucrecio Caro, Tito: [De rerum natura. Español] Lucrecio: Sobre la naturaleza de las cosas / traducido por M[atías] S[ánchez] P. —, S. XIX (1810-1832).-- [1] h.+207 f.+[28] h. : papel ; 210x150 mm. ; + carta original, (300x218 mm.).-- h. [1] r-v: [Carta autógrafa de J. Ma . Cambronero, secretario de la Real Academia GrecoLatina, dirigida a D. Matías Sánchez, en la que elogia la traducción de Lucrecio y, por su literalidad, recomienda que no se publique. Madrid, 29 de diciembre de 1832. Firmada y con sello estampado de 1832] f. 1r: [Fragmento tomado de las Confesiones de San Agustín] f. 1v: A los estudiosos. f. 201r-207r: Notas.

\section{El texto de los mss. II 646 y 287 y la edición de Menéndez Pelayo (1896): variantes, lagunas y modificaciones}

En el título de la traducción manuscrita se leen las iniciales del presbítero Matías Sánchez en letra itálica (f. 1 r.):

\section{Lucrecio / Sobre la Naturaleza de las cosas. / traducido por M. S. P.}

La M. y la S. las restituyó fácilmente el informe anexo, pero la P., no. Importa poco ahora, salvo para conocer su verdadera identidad ${ }^{29}$, si la P. era de Pérez, Pala-

29 Encuentro en la "Lista de señores suscriptores" de Aparisi y Guijarro (1877, 503), donde se dan datos de sus nombres, apellidos y pueblos, un «Matías Sánchez García, Presbítero, Velez-Rubio». 
cios o Pulido, o si era una abreviatura incorrecta de "presbítero" (Pbro.). Tampoco era la A. abreviatura francesa de "Abbé" $30 \mathrm{y}$, sin embargo, Michel de Marolles en la portada latina de su segunda edición (1659) abrevió su nombre y cargo eclesiástico con las siglas M. D. M. A. D. V. ("Michel de Marolles, Abbé de Villeloin"31). Daba igual, de haberse publicado no habría tardado mucho tiempo en saberse que su verdadero nombre era Matías Sánchez. Ya le había ocurrido al propio Michel de Marolles, al publicar la primera versión francesa en 1650 con las iniciales M. D. M. Algunos compradores escribieron debajo expandido su nombre: "Michel de Marolles"32.

Es posible que para su versión, aparte del texto latino, usara o la traducción italiana de Alessandro Marchetti, dado que está compuesta en endecasílabos sueltos como la suya ${ }^{33}$, o la traducción francesa con texto latino de Jacques Parrain, Baron des Coutures (1645-1702), como parece apuntar el fragmento de las Confesiones (6.16) de San Agustín ${ }^{34}$, citado justo debajo del título (f. 1 r.) y que reproduzco a continuación:

Disputabam cum amicis meis Alipio et Nebridio de finibus bonorum et malorum, Epicurum accepturum fuisse palmam in animo meo, nisi ego credidissem post mortem restare animae vitam, et tractus meritorum, quod Epicurus credere noluit.

Sigue en el f. 1 v. la tradicional advertencia o, como Prosperi (2004, 107-11) bien acuñó, la damnatio Lucretii ${ }^{35}$. Con ella Matías Sánchez advierte y manifestaba pública repulsa por los deliramenta Lucretii ${ }^{36}$, esto es: las tesis de la mortalidad del alma y la no existencia de la vida ultraterrena, argumentadas por el epicúreo romano con una treintena de razones en el libro 3 del De rerum natura ${ }^{37}$. Está compuesta en endecasílabos sueltos y parafrasea casi hasta el final la cita agustina. Reza así:

\section{A los estudiosos}

Solo a vosotros, hombres estudiosos, Dedico los escritos de este sabio,

30 Era «Abb.». Cf. su retrato y cartela tras el "Extraict du Privilege du Roy" (Marolles 1656).

31 De Rerum Natura Libri sex Ad postremam Oberti Gifani I. C. emendationem accuratissimè restituti; cum interpretatione Gallica M. D. M. A. D. V., Lutetiae Parisiorum: Ap. Guillelmum de Luyne, 1659 (BN R/20248).

32 Cf. la imagen de uno a la venta en "Leclere Maison de Ventes" (París) en este enlace http://leclere-mdv.com/ html/fiche.jsp?id=9808957 (consultado 01/12/2019).

33 Del prestigio que tuvo en su tiempo, nos da noticias la Poética del ilustrado Ignacio de Luzán (1789 I, 373 ): «Resta ahora decir algo de los versos sin rima ni asonante, que llamamos sueltos, enteramente desconocidos en la poesía castellana [...] Los italianos han sido más constantes; pues, el siglo pasado, cuando también allí se pervirtió el estilo, hizo el Marchetti, en versos sueltos, su famosa y elegantísima traducción de Lucrecio».

34 La cita aparece en su edición de 1695 (A Lyon: Chez Horace Molin, p. 345). Esta traducción francesa con texto latino y notas tuvo numerosas reimpresiones, como detalla Gordon (1985, 156-59). También aparece la cita con el nombre Alipio y no Alypio en P. Gassendi, Animadversiones in decimum librum Diogenis Laertii, p. 113 (Opera Omnia. Tomus quintus, Florentiae: Typis Regiae Celsitudinis, 1727).

35 Estudié varias de ellas en mi tesis (2009, 264-88).

36 Expresión del insigne impresor veneciano Aldo Manucio, cuya damnatio, expresa en su prefacio a la edición de Avancio (Venecia, 1500), sirvió de referencia a las posteriores (Palmer 2014, 205).

37 Como recuerda el propio Matías Sánchez en las notas introductorias al libro 3: «Dice en fin que el alma, y el cuerpo nacen y mueren a un tiempo; dogma impio que prueba con treinta argumentos, refutado sabiamente por Gassendi» (f. 72 r.). 
De aquel varon romano, cuyos labios

La divina natura sublimaron

Esplicando sus obras admirables.

De mi pecho triunfava sin disputa,

Dice el grande Agustino, la doctrina

Del filosofo griego, si no fuera

Por sentar que perecen nuestras almas,

Y que no hay galardon en la otra vida,

Ni corona de gloria para el justo,

Ni castigo para hombres desalmados.

A nosotros nos basta Jesucristo;

El es nuestra salud, nuestro consuelo;

Por el daremos toda nuestra sangre,

Su ley es dulce, facil, muy humana:

En el ponemos nuestra confianza

Sin temer el furor de los tiranos

Entre los argumentos y las notas de cada libro, relativamente extensas, se desenvuelve el texto lucreciano a lo largo de los siguientes folios (2 r.-207 r.). El ductus del amanuense es firme y bastante claro $^{38}$. Empieza con una media de veinte dos versos por cara y termina con un promedio de treinta y dos. También el trazo del copista del ms. $287^{39}$ es constante y claro, en mi opinión, aunque con una media de veinte versos por cara.

Si comparamos el ms. II 646 y la edición de Menéndez Pelayo (1896) el número de versos por libros es el siguiente:

\begin{tabular}{|l|l|c|c|c|c|c|c|c|}
\hline Mss. / Ed. & Autor & I & II & III & IV & V & VI & Total \\
\hline II 646 & Matías & 1401 & 1538 & 1511 & 1776 & 2121 & 1895 & 10242 \\
\hline Ed. & M. Pelayo & 1402 & 1531 & 1504 & 1770 & 2113 & 1891 & 10221 \\
\hline $\mathbf{2 8 7}$ & Marchena & & 1531 & & & & 1894 & \\
\hline
\end{tabular}

Veintiún versos de diferencia no son muchos, si tenemos en cuenta que la musa de Menéndez Pelayo hizo variar el cómputo final del ms. 287, pues suprimió y modificó versos $^{40}$. Los libros II y VI del ms. 287, por ejemplo, suman $1531^{41}$ y 1894 endecasílabos respectivamente. Traemos tres ejemplos:

38 Dudo que sea autógrafo. Matías Sánchez era miembro de número de la Academia Greco-Latina. En el comento del verso VI 480 (Urget enim quoque signiferi super aetheris aestus) el escribiente -suponemos- comete dos errores seguidos: citando el hexámetro signiferi super aetherii y luego al explicarlo aestus aetherii signiferi (f. 203 r.). Es difícil pensar que el académico cometiera este error.

39 Menéndez Pelayo (1896, XI) apuntó la posibilidad de que fuera copia del original. Según Pablo Asencio (2013, 422), la letra de este ms. y la de José Marchena no se parecen.

40 Solo en el primer libro el total de endecasílabos de la edición supera por un verso al ms. de Matías Sánchez, a causa -creemos- del verso 924 ("o de inmortal estirpe descendiente"), seguramente añadido por Menéndez Pelayo y que ampliaría la traducción del hexámetro I 733 ( ut vix humana videatur stirpe creatus).

41 Aunque el total de versos indicado en el margen izquierdo del f. 72 v. es de 1564, otra numeración a la derecha y de distinta mano lo corrige, dando como suma 1531. 


\section{i. LuCR.4.18-22 (supresión)}

\section{Ed. Menéndez Pelayo}

vv. $24-29$

Así yo ahora, pareciendo austera Y nueva y repugnante esta doctrina Al común de los hombres, exponerte Quise nuestro sistema con canciones Suaves de las Musas, y endulzarle Con el rico sabor de poesía:
Ms. 287

vv. 24-30 (f. 112 r.)

asi yo aora pareciendo austera por lo comun esta filosofía para quienes es nueva y repugnante casi a todos los hombres, esponerte quise nuestro sistema con canciones suaves de las musas, y endulzarle con el rico sabor de poesia.

\section{Ms. II 646}

vv. 24-30 (f. 101 r.)

Asi yo aora pareciendo austera Por lo comun esta filosofia Para quienes es nueva, y repugnante Casi a todos los hombres; esponerte Quise nuestro sistema con canciones Suaves de las musas, y endulzarle Con el rico sabor de poesia:

\section{ii. LUCR.4.1168-70 (supresión)}

\section{Ed. Menéndez Pelayo}

vv. $1602-5$

Y si gorda y tetuda, es una Ceres, La querida de Baco: si chatilla, Es silla de placer; ¡nadie podría Enumerar tan ciegas ilusiones!
Ms. 287

vv. 1625-29 (f. 141 r.)

y si gorda y tetona, es una Ceres, la querida de Baco: si chatilla, es silla de placer; si belfa, el beso: jamás acabaría, si intentara contar las ilusiones de esta especie.

\section{Ms. II 646}

vv. $1604-8$ (f. 125 v.)

Y si gorda y tetona, es una Ceres, La querida de Baco: si chatilla, Es silla de placer; si belfa, el beso: Jamas acabaria, si intentara Contar las ilusiones de esta especie.

\section{iii. LUCR.5.1379-83 (modificación)}

\section{Ed. Menéndez Pelayo}

$$
\text { vv. 1993-2000 }
$$

Mas los claros gorjeos de las aves Con la voz se imitaban mucho antes Que pudiesen los hombres regalarse Los oidos con versos armoniosos De melódico són y dulce halago; Y el silbido del céfiro en los huecos De las cañas les dió lección primera De inflar la campesina cañaheja.
Ms. 287

$$
\text { vv. 1996-2003 (f. } 207 \text { r.) }
$$

Mas los claros gorgeos de las aves con la voz se imitaban mucho antes que pudiesen los hombres regalarse los oidos con bersos armoniosos, con los hechizos de la melodía; y el silvido del Zefiro en los huecos de las cañas dió la leccion primera de inflar la campesina cañaheja.

\section{Ms. II 646}

vv. 2006-13 (f. 165 v.)

Mas los claros gorgeos de las aves Con la voz se imitaban mucho antes Que pudiesen los hombres regalarse Los oidos con versos armoniosos, Con los hechizos de la melodía:

Y el silvido del Zefiro en los huecos De las cañas dió la leccion primera De inflar la campesina cañaheja.

Aparte de esta ligera variación numérica, presente en la edición debida a la inspiración del santanderino, el ms. 287 presenta lagunas, de las cuales hallo tres, dos de ellas debidas a omisión por homoeoteleuton o "saut du même au même" (Willis 1972, 111-18). Estas son:

\section{i. LUCR.3.882-89 (Libro 3.1207-210) ${ }^{42}$}

\section{Ms. 287}

vv. $1220-23^{43}$ (f. 103 v.)

\section{646}

vv. 1208-1217 (f. 92 r.-v.)

42 Seguimos para la numeración del texto latino la edición de Munro (1886). La referencia entre corchetes corresponde a la ed. de Menéndez Pelayo (1896). En cada columna, inserto la correspondiente de cada manuscrito.

43 Esta laguna de Lucr.3.884-87 fue señalada por Plácido (1999 224, n. 16) en la edición de Agustín García Calvo (1999) del De la naturaleza de las cosas de José Marchena. 
que existe aun, y sin dejar su lado le anima con su propio sentimiento: porque si es ciertamente una desgracia en la muerte servir de pasto á fieras,
Que existe aun, y sin dejar su lado Le anima con su propio sentimiento: Indignase por eso haber nacido Mortal: no ve que verdadera muerte Subsistir otro el no le permite; Un otro vivo que llorarle pueda

Despues de muerto estando en pie a su lado Comido de dolor y sentimiento:

Porque si es ciertamente una desgracia

En la muerte servir de pasto a fieras,

\section{ii. LuCR.4.1157-60 (Libro 4.1583-86)}

\section{Ms. 287}

vv. $1606-9^{44}$ (f. 140 v.)

el aplacar á Venus mutuamente que los aflige con amor infame: si es negra su querida, para ellos es morenita muy graciosa;

\section{iii. LUCR.5.339-43 (Libro 5.475-77)}

Ms. 287

vv. $477-79^{45}$ (f. 168 r.)

con voraz llama las generaciones ${ }^{46}$, o que se destruyeron las ciudades, debes decir tanto más convencido

\section{646}

vv. 1583-88 (f. 125 r.-v.)

El aplacar a Venus mutuamente,

Que los aflige con amor infame:

Victimas son al fin los pobretones

De objeto mas disforme, y vergonzoso:

Si es negra su querida, para ellos

Es una morenita muy graciosa;

\section{646}

vv. $476-83$ (f. 142 v.)

Con voraz llama las generaciones, $\mathrm{O}$ que se destruyeron las ciudades

Con las revoluciones espantosas

Del mundo; o que torrentes destructores

Se desencadenaron sobre el globo

A causa de las lluvias continuadas,

Y dejaron cubiertas las ciudades:

Tanto mas convencido decir debes

Dado que de los dos homoeoteleuta solo uno (iii) se encuentra en la misma cara de folio del ms. II 646, es probable que el original presentara los homoeoteleuta en sendas caras de folios y provocara las omisiones en el ms. 287. Pero hay, al margen de estas lagunas textuales, otros errores en el ms. 287 que apuntarían a que es una copia deturpada del ms. II 646, dado que Matías Sánchez traduce del latín, mientras que el amanuense del "ms. marcheniano" copia mal la traducción castellana. Traemos una muestra de las que hemos encontrado.

44 Menéndez Pelayo se percató de que la numeración no era la correcta y en el v. 1600 tachó los dos primeros dígitos (f. $190 \mathrm{v}$.).

45 Plácido $(1999,304)$ indicó también que en la traducción del ms. 287 faltaban los versos de Lucr.5.341-42.

46 Menéndez Pelayo llamó la atención rodeándolo con un círculo y haciéndole tachaduras perpendiculares. A su derecha escribió el número 476, referido seguramente al orden correcto que ocupaba, en su opinión, dentro de este fragmento. De hecho, en el ms. de Matías Sánchez es el verso 476. 


\section{i. LUCR.2.367-370}

Escribe el poeta epicúreo:

praeterea teneri tremulis cum vocibus haedi cornigeras norunt matres agnique petulci balantum pecudes: ita, quod natura reposcit, ad sua quisque fere decurrunt ubera lactis.

[Además los tiernos cabritos conocen a sus cornudas madres dando trémulas voces y los corderos topadores, a las ovejas baladoras: de este modo, como la naturaleza reclama, allá que se precipita cada uno a sus ubres de leche.]

Matías Sánchez vierte el pasaje de esta guisa (vv. 480-84. F. 48 v.):

Conocen ademas los tiernos chotos

Con voz temblosa a las cornudas madres;

Y balantes corderos topadores (:)

Asi guiados por Naturaleza

A mamar corren las lecheras ubres.

El verso 482 del ms. II 646 tiene dos puntos finales borrados después de «topadores». Pero son visibles, por lo que el amanuense del ms. 287 los copia (vv. 481-85. F. 45 r.):

Conocen ademas los tiernos chotos con voz temblosa á las cornudas madres, y balantes corderos topadores:

y así, guiados por naturaleza, ${ }^{48}$

á mamar corren las lecheras ubres.

La confusión en la puntuación hace que el sentido de la traducción del ms. 287 y, en consecuencia, el de la edición de Menéndez Pelayo, difiera un poco de la del ms. II 646. Este afirma "Además los tiernos chotos conocen a las cornudas madres con voz temblosa, y (los) balantes corderos topadores así guiados por Naturaleza corren a mamar las lecheras ubres". En cambio, según el ms. 287, la oración diría “Además los tiernos chotos y (los) balantes corderos topadores conocen a las cornudas madres con voz temblosa, y así, guiados por naturaleza, corren a mamar las lecheras ubres". Ahora bien, las ovejas, en su mayoría, no tienen cuernos, algo que no debió de pasarle desapercibido a Matías Sánchez cuando traducía el texto latino, donde claramente

47 Seguimos para el texto latino la edición de Munro (1886).

48 Las comas de este verso han sido añadidas -imaginamos- por Menéndez Pelayo, dado su trazo alargado, inusual en el copista. En cambio, la $y$ inicial del verso parece original de este. 
cornigeras matres está asociado a teneri haedi y balantum pecudes, a agni petulci (LuCR.2.367-70).

Menéndez Pelayo (1896, 56, vv. 477-80) termina editando el ms. 287 de este modo:

Conocen además los tiernos chotos

Con voz temblosa á las cornudas madres

Y balantes corderos topadores:

Y así, guiados por naturaleza,

Á mamar corren las lecheras ubres.

\section{ii. LUCR. 6.1160-62}

Al referir los últimos síntomas de la peste, escribía Lucrecio estos versos:

singultusque frequens noctem per saepe diemque

corripere adsidue nervos et membra coactans

dissoluebat eos, defessos ante, fatigans.

[Y el estertor frecuente, muchas veces a lo largo de noches y días, que forzaba a los nervios y miembros a contraerse asiduamente, fatigándolos, los aniquilaba ya exhaustos.]

Matías Sánchez los tradujo de esta suerte (vv. 1715-20ª F. 198 v.):

Y sollozar perene noche y dia,

Que sin cesar los nervios irritando,

Envarando los miembros, desatando

Las articulaciones, consumian

A los que sucumbian ya cansados

A la fatiga.

Y el escribano del ms. 287 corrige (vv. 1713-18 a F. 255 v.):

y sollozar perenne noche y día, que sin cesar los nervios irritando, embarando los miembros, desatando las articulaciones, consumian á los que sucumbian ya cansados á la fatiga.

El adjetivo «perenne» no figura en el texto latino, salvo por la secuencia análoga per saepe y el adjetivo frequens. En el ms. II 646 aparece «perene», hoy en desuso, pero equivalente a "perenne", más común y latino. Añade el copista del 
ms. 287 "n", pero abajo escribe «embarando» de forma incorrecta ${ }^{49}$. Matías Sánchez escribe este verbo correctamente, aunque su " $n$ " inicial parece una " $m$ ". Es posible, pues, que el propio copista, leyendo "m", corrigiese de nuevo el término, aunque mal. Cabría suponer, también, que el error ya estuviera en otro ejemplar del que el ms. 287 es copia.

\section{iii. LUCR.6.1190-92 ${ }^{\mathrm{a}}$}

Dice así el texto latino:

in manibus vero nervi trahere et tremere artus a pedibusque minutatim succedere frigus non dubitabat.

[Es más, en las manos los nervios se contraían y los miembros temblaban y desde los pies no dudaba en ascender poco a poco el frío de la muerte]

Matías Sánchez lo traduce de esta forma (vv. 6.1757-60ª. F. 199 r.):

Los nervios de las manos se atiesaban, Tiritaban los miembros, y subia

El frio de la muerte poco a poco

Desde los pies al tronco:

El ms. 287 transcribe (vv. 1756-59 ${ }^{\text {a }}$. F. 256 v.):
Se aticiaban los nervios de las manos, los miembros tiritaban; y subía el frio de la muerte poco a poco desde los pies al tronco:

En el ms. II 646 «atiesaban» recoge bien el sentido de nervi trahere; pero la $e$ parece una $c$ y la $s$ parece una $i$ sin punto $(l)$, de ahí que el copista del ms. 287 escriba «aticiaban». Menéndez Pelayo mantiene este término, a pesar de que el verbo "aticiar" no existe. La posición inicial de «se aticiaban», en cambio, no apoyaría la dependencia directa del ms. 287 sobre el II 646, salvo que el trastorno fuera debido a un despiste del amanuense mientras intentaba descifrar el término, que afecta también al verso siguiente, pues en II 646 el orden es «Tiritaban los miembros». Y comparadas las traducciones de estos dos versos, la del presbítero respeta mejor el orden latino (nervi trahere et tremere artus).

49 Se aprecia la corrección de la m y la b de Menéndez Pelayo, que las tacha. 
iv. LUCR. 6.1230-33

Casi al final del libro VI, versifica Lucrecio:

illud in his rebus miserandum magnopere unum aerumnabile erat, quod ubi se quisque videbat implicitum morbo, morti damnatus ut esset, deficiens animo maesto cum corde iacebat,

[en estas circunstancias lo más lamentable era que, cuando se veían contagiados, yacían abatidos y entristecidos, como si hubieran sido condenados a muerte]

El ms. II 646 lo traduce así (vv. 1813-17. F. 200 r.):

Pero alli lo mas triste y deplorable Era que algunos de estos infelices, Que se veian presa del contagio Se despechaban como criminales Condenados a muerte, se abatian.

El ms. 287, por su parte, lo vierte de este modo (vv. 1811-15. F. 258 r.):

Pero alli lo mas triste y deplorable era que algunos de estos infelices que se veian presa del contagio se despachaban como criminales condenados á muerte, se abatian.

Menéndez Pelayo (1896, 301, vv. 1808-12) mantiene «se despachaban» del ms. 287, que no guarda bien el sentido de desesperarse (maesto cum corde iacebat). Sin embargo, el verbo "despecharse", sí lo hace ${ }^{50}$. Y curiosamente Agustín García Calvo $(1999,408$, v. 1801) reintegra, con su consabida agudeza, «se despechaban» en su edición de la supuesta traducción del abate Marchena.

\section{Conclusiones}

Hacer aseveraciones categóricas en cuestiones de transmisión textual, cuando no se han escrutado con la minuciosidad de un entomólogo los mss. implicados, resulta siempre peregrino. Y no las voy a hacer, dado que no he examinado en su integridad el ms. 287. Con todo, opino, a tenor de los datos y argumentos expuestos, que el ms. II 646 es mejor que el 287, y, de ser así, las dudas de si este último es autógrafo o no de José Marchena (Menéndez Pelayo 1896, XI, y Asencio 2013, 422), no tendrían ya cabida.

50 Según el Diccionario de autoridades (1732, 210b): «Desesperarse, entregarse al furor y despécho. Latín. In rabiem agi $[\ldots]$ Vale también perder la esperanza de conseguir algún fin». 
Respecto a la autoría de la traducción, asunto medular de este artículo, hay, a mi modo de ver, indicios suficientes para creer que la versión del De rerum natura en endecasílabos sueltos contenida en ambos mss. es original de Matías Sánchez y no de José Marchena, salvo por la fecha de «1791», presente tanto en la portada (f. $1 \mathrm{r}$ ) como en el colofón del ms. 287 (f. 260 v.), y las iniciales «J. R. M. C.», expresas solo en su colofón. Pero desconfío de ellas, no solo porque la letra del colofón es de una mano distinta de la del cuerpo de traducción y de la portada primitiva ${ }^{51}$, sino también porque las portadas y colofones suelen ser pasto de terceros, donde se escriben todo tipo de anotaciones y, si se tercia, se modifican títulos y nombres, más, si cabe, en la obra de un poeta damnatus y prohibido en vulgar ${ }^{52}$ como el De rerum natura de Lucrecio $^{53}$.

Apoyarían esta hipótesis de la autoría de Matías Sánchez claramente los datos documentales y, en menor medida, los textuales. Entre los primeros, sobresalen la presentación de su traducción a una institución pública como la Academia GrecoLatina, su condición de religioso, como los abates Michel de Marolles y Raffaele Pastore; el informe de Don José Cambronero y los oficios de compra por parte de la Biblioteca del Palacio Real. Entre los segundos, destacan un texto más completo, sin lagunas como LuCR.3.884-87, 4.1159 y 5.340-42; las variantes, más respetuosas con el orden y sentido de los hexámetros lucrecianos, que probarían que el ms. 287 es una copia deturpada de la "rama o familia" del II 646; las notas a versos concretos del De rerum natura, tomadas y contrastadas, en ocasiones, a partir de comentarios críticos de editores reputados de Lucrecio, como Thomas Creech y Pierre Gassendi, que tienen reflejo en su traducción ${ }^{54}, \mathrm{y}$, por último, las piezas literarias presentes desde el Renacimiento hasta el siglo XIX en la tradición editora de Lucrecio: cita, damnatio Lucretii, argumentos y notas.

Incluso el ex libris del Colegio Imperial de los Jesuitas, presente en la portada del ms. 287, podría explicar la existencia misma de esta copia, pues la Academia GrecoLatina se ubicó, al menos, durante 1842 en este prestigioso colegio madrileño ${ }^{55}$. Y recordemos el sentir de Menéndez Rayón (Revuelta Sañudo 2008, I 302): «Yo creo que este escrito ( $s c$. el ms. 287) se ha hecho aqui (sc. en Madrid) y debió hacerse del 30 al 40, poco mas o menos, por el original». Y, llegados a este punto, convendría re-

51 Según Artigas y Sánchez Reyes (1957, 101, n 59) decía: «Lucrecio. De rerum Natura| Poema en 6 Cantos en Verso | escritos en Valmojado | año de 1791».

52 El Índice último de Rubin de Cevallos $(1790,165)$ prohibía la traducción italiana de Marchetti en estos términos: «Lucretio Caro (Tito). Della natura delle cose. Libri 6 tradotti del latino, \&c Da Alexandro Marchetti. Amsterd. 1754. 2 tom. Edicto de 20 de Jun. de 1779: por estar en vulgar, y por su laminas obscenas».

53 El ejemplo más ilustrativo, en el caso de la tradición manuscrita del De rerum natura, sería el de los códices Oblongus y Quadratus, como recuerda Bailey (1998 II, 583): «In O there is space from which it may have been erased (sc. De rerum natura). Q had the title of which T. remains and LVCRETI is just traceable in erasure; then follows the substituted title DE PHISICA RERVM ORIGINE ET EFFECTV LIBER PRIMVS INCIPIT, which is no doubt a clerical alteration made at a time when Lucretius was in bad odour with the Church as an 'atheist'».

54 Cf. la nota al verso latino VI 480 (f. 203 r.): «Urget enim quoque signiferi super aetherii aestus. El aestus aetherii signiferi no puede significar el calor de la boveda eterea, como dice Gassendi; porque en sentir de Creech es propio del calor dilatar y enrarecer, pero no condensar y hundir. Aqui se trata solo de la materia eterea, que pasando por encima de las nubes las comprime, y las da consistencia. Terrena in coelum tendentia deprimit syderum vis, dice Plinio el naturalista». Y traduce así el verso Matías Sánchez (VI 701-3, f. 182 v): «pues las olas / De la materia eterea las empujan / Por la parte de arriba». $C f$. Creech $(1818,367, a d 480)$.

55 Allí lo sitúan la Guía de litigantes y pretendientes para el año de 1842 (Nifo 1841, 115) y la Guía de forasteros del mismo año $(1842,234)$. En la primera aparece como «Académico de número» el «Sr. D. Matías Sánchez, presbitero» (p. 116). Esta sería la última fecha cierta, hasta ahora, de su vida. 
considerar también si esta traducción, atribuida a Marchena, circuló manuscrita entre un reducido número de personas, pues parece, más bien, que estuvo a buen recaudo.

Otras pruebas y valoraciones vendrán de un cotejo y análisis concienzudo sobre estos mss., como el hecho de que Matías Sánchez traduzca el término religio como "fanatismo". Al ser sacerdote, sabía que de acuerdo con la tradición patrística cristiana el término aludía a la religión pagana ${ }^{56}$. Y queda despejar las tinieblas en torno al presbítero Matías Sánchez, sobre el que se cierne, como tantas veces en la tradición lucreciana (Farrington 1939, 191-217), un silencio que suena a conjura ${ }^{57}$.

\section{Referencias bibliográficas}

Aguilar Piñal, F. (1993² [1983]), Bibliografía de autores españoles del siglo XVIII, vol. 7, Madrid, CSIC.

Aparisi y Guijarro, A. (1877), Obras. Tomo V: Escritos y discursos forenses, Madrid, Imprenta de A. Florez y Compañía, <https://books.google.es/books/ucm?vid=UCM5324966912> [consultado 01/12/2019].

Artigas, M. y E. Sánchez Reyes (1956), Catálogos de los manuscritos de la Biblioteca Menéndez y Pelayo por sus Directores, Santander, Taller de Artes Gráficas de los Hermanos Bedia, <http://www.marseca.es/bibliotecademenendezpelayo/pdf/Catalogo_\%20Artigas. pdf $>$ [consultado 01/12/2019].

Asencio Sánchez, P. (2013), «Marchena: clasicismo e historicismo entre los siglos XVIII y XIX», en García Jurado, F., González Delgado, R. y González González, M. (eds.), La historia de la Literatura Grecolatina en España: de la Ilustración al Liberalismo (17781850). Analecta Malacitana. Anejo XC, Málaga, Universidad de Málaga, 415-42.

Bailey, C. (1998² [1947]), Titi Lucreti Cari: De rerum natura libri sex, (prolegomena, critical apparatus, translation, and commentary), 3 vols., Nueva York, Oxford UP.

Blanco García, F. (1891), Historia de la Literatura Española en el siglo XIX, 3 vols., Madrid, Sáenz de Jubera Hermanos, Editores, <http://bdh-rd.bne.es/viewer.vm?id=0000014616> [consultado 01/12/2019].

Canella Secádes, F. (1903-1904³ [1873]), Historia de la universidad de Oviedo y noticias de los establecimientos de enseñanza y de su distrito (Asturia y León), Oviedo, Imp. de Flórez, Gusano y C.a, <http://bdh-rd.bne.es/viewer.vm?id=0000228889> [consultado 01/12/2019].

Costa, G. (2012), Epicureismo e pederastia: Il "Lucrezio" e l' "Anacreonte” di Alessandro Marchetti secondo il Sant'Uffizio, Florencia, Leo S. Olschki.

Creech, Th. (1818), Titi Lucreti Cari De rerum natura libri sex, Oxonii, e Typographeo Clarendoniano <https://books.google.es/books?id=KvJDAAAAYAAJ $>$ [consultado 04/12/2019].

56 Traduce, así, Lucr.1.62-63: «Cuando la humana vida claramente / Oprimida yacia con infamia / En la tierra por grave fanatismo» (vv. 88-90. Ff. 4 v.-5 r.). Cf. la nota aclaratoria de Plácido (1999, 94, n. 3). Sobre la traducción del término religio en las primeras traducciones castellanas del De rerum natura, cf. López Castillo (2018, 17 30).

57 Aparte de indagar en archivos eclesiásticos, Hualde Pascual y García Jurado (2005, 211-15) relacionan documentación original de la Academia Greco-Latina que puede aportar, a primera instancia, datos biográficos o del expediente académico del sacerdote. De gran ayuda sería dar con el expediente de censura, pues, según Hualde Pascual y García Jurado $(2004,195)$, se han conservado «treinta y nueve obras censuradas entre octubre-noviembre de 1830 y septiembre de $1833 »$. 
Diccionario de autoridades (1732), En Madrid, En la imprenta de la Real Académia Españóla, $<$ https://books.google.es/books?id=SC2WaRiQUOEC $>$ [consultado 01/12/2019].

El Corresponsal (Domingo, 12 de Setiembre de 1841), no. 834, p. $4<\mathrm{http}$ ://hemerotecadigital. bne.es/issue.vm?id=0029052616\&page $=4>$ [consultado 01/12/2019].

Escapa, P. A. et al. (1994-1995), Catálogo de la Real Biblioteca, 3 vols., Madrid, Patrimonio Nacional. Farrington, B. (1939), Science and politics in the Ancient World, Londres, G. Allen \& Unwin ltd. Flores, E. (1980), Le scoperte di Poggio e il testo di Lucrecio, Nápoles, Liguori Editrice.

Forcada Torres, G. (1966), «Ingleses, españoles y franceses en los prolegómenos de la batalla de Tudela», Príncipe de Viana 102-103, 137-68.

Fuentes, J. F. (1989), José Marchena: Biografía politica e intelectual (Temas Hispánicos 191), Barcelona, Editorial Crítica.

García Armendáriz, J.-I. (2002), «Lucrecio en la España de Fernando VII», en Aa. Vv. (eds.), Neoclásicos y románticos ante la traducción, Murcia, Universidad de Murcia, 103-118.

García Calvo, A. (19994 [1983]) y D. Plácido (nn.), Lucrecio: De la naturaleza de las cosas (Letras Universales 4), Madrid, Cátedra.

Gómez de Olea, J. y P. Moreno Mayerhoff(2007), «Los Condes de Fuentes. La Casa Pignatelli (Siglos XVIII-XXI). $2^{a}$ parte», Anales de la Real Academia Matritense de Heráldica y Genealogía 10, 211-304.

Gordon, C. A. (1985² [1962]), A bibliography of Lucretius, Londres, R. Hart-Davis.

Guía de forasteros en Madrid para el año de 1842, Madrid, En la Imprenta Nacional, <http:// hemerotecadigital.bne.es/issue.vm?id=0002229471> [consultado 03/12/2019].

Gutiérrez del Caño, M. (1992² [1913]), Catálogo de los manuscritos existentes en la Biblioteca Universitaria de Valencia (Biblioteca Valenciana), 3 vols., Valencia, Librerías "ParisValencia", <http://bdh-rd.bne.es/viewer.vm?id=0000134147> [consultado 04/12/2019].

Hualde Pascual, P. y F. García Jurado (2004), «La Academia (Greco)Latina matritense (17551848). Primera parte: su historia», Minerva(vall) 17, 165-202.

Hualde Pascual, P. y F. García Jurado (2005), «La Academia (Greco)Latina matritense (17551848). Segunda parte: actividad filológica y documentos», Minerva(vall) 18, 211-25

La Correspondencia de España (Viernes, 10 de Noviembre de 1871), nº 5097, p. $3<\mathrm{http}: / /$ hemerotecadigital.bne.es/issue.vm?id=0000137961\&page $=3>$ [consultado $01 / 12 / 2019$ ]

López Castillo, M. (2018), «El término religio en las primeras traducciones del De Rerum Natura en España», en Abello Verano, A., Arciello, D. y Fernández Martínez, S. (eds.), La escritura y su órbita: nuevos horizontes de la crítica literaria hispánica, León, Universidad de León, 17-30.

López Tabar, J. (2014), «Manuel M ${ }^{\mathrm{a}}$ Cambronero (1764-1834): avatares de un jurista en el tránsito del Antiguo al Nuevo Régimen», Ayer 95, 79-108.

Luzán, I. de (1789), La Poética, ó Reglas de la poesía en general, y de sus principales especies, 2 vols., Madrid, En la Imprenta de D. Antonio de la Sancha, < http://bdh-rd.bne. es/viewer.vm?id=0000013601 $>$ [consultado 04/12/2019]

Marolles, M. de (1656), Les memoires de Michel de Marolles, Abbé de Villeloin, vol I, A Paris, chez Antoine de Sommaville, <https://gallica.bnf.fr/ark:/12148/bpt6k82666p/f2.image. $\mathrm{r}=\mathrm{Les} \% 20$ memoires\%20de\%20Michel\%20de\%20Marolles $>$ [consultado 01/12/2019].

Mendive, J. (1887² [1883]), La religión católica vindicada de las imposturas racionalistas, Madrid, Librería Católica de Gregorio del Amo, <http://bdh-rd.bne.es/viewer. vm?id=0000244803 $>$ [consultado 01/12/2019].

Menéndez Pelayo, M. (1880-1881), Historia de los heterodoxos españoles, 3 vols., Madrid, Librería católica de San José <http://bdh-rd.bne.es/viewer.vm?id=0000227244> [consultado 01/12/2019]. 
- (1896), Obras literarias de D. José Marchena (El abate Marchena); recogidas de manuscritos y raros impresos con un estudio crítico-biográfico del Doctor D. Marcelino Menéndez y Pelayo, vol. 2, Madrid, Imp. de E. Rasco, <https://archive.org/details/ A2260223> [consultado 01/12/2019].

Molina Sánchez, M. (2018), «¿Matías Sánchez traductor de Lucrecio?», Cuad. Filol. Clás. Estud. Lat. 38.2, 345-353, <https://revistas.ucm.es/index.php/CFCL/article/view/62529> [consultado 01/12/2019].

Munro, H. A. J. (1886 [1864]), T. Lucreti Cari De rerum natura libri sex, vol. I (with notes and a translation), Cambridge, Deighton Bell and Co.

Nifo, M. (1828), Guía de litigantes y pretendientes para el año de 1828, Madrid, Imprenta de Ibarra, <http://hemerotecadigital.bne.es/issue.vm?id=0001272015> [consultado 30/11/2019].

- (1830), Guía de litigantes y pretendientes para el año de 1830, Madrid, Imprenta de Ibarra, $<$ hemerotecadigital.bne.es/issue.vm?id=0001273413 > [consultado 30/11/2019].

- (1835), Guía de litigantes y pretendientes para el año de 1835, Madrid, Imprenta de Núñez, $<$ http://hemerotecadigital.bne.es/issue.vm?id=0001276896 > [consultado 30/11/2019].

- (1837), Guía de litigantes y pretendientes para el año de 1838, Madrid, Imprenta de D. Norberto Llorenci, <http://hemerotecadigital.bne.es/issue.vm?id=0001277988> [consultado 30/11/2019].

- (1841), Guía de litigantes y pretendientes para el año de 1842, Madrid, Imprenta de D. Norberto Llorenci, <http://hemerotecadigital.bne.es/issue.vm?id=0001279501> [consultado 30/11/2019].

Norbrook, D. (2016), «Introduction», en Norbrook, D., Harrison, St. y Hardie, Ph. (eds.), Lucretius and Early Modern (Classical Presences), Oxford, Oxford UP, 1-27.

Palmer, A. (2014), Reading Lucretius in the Renaissance (I Tatti Studies in Italian Renaissance History), Cambridge, Harvard UP.

Plácido, D. (19994 [1983]), «Notas», en García Calvo, A. (ed.), Lucrecio: De la naturaleza de las cosas (Letras Universales 4), Madrid, Cátedra.

Prosperi, V. (2004), "Di soavi licor gli orli del vaso". La fortuna di Lucrezio dall'Umanesimo alla Controriforma (Centauri), Turín, Nino Aragno Editore.

Prosperi, V. (2005), «Traduttori italiani di Lucrezio (1800-1902)», Eikasmos 16, 419-70.

Ramos Santana, C. (2002), «Traductores de las Bucólicas de Virgilio en la primera mitad del siglo XIX», en Aa. Vv. (eds.), Neoclásicos y románticos ante la traducción, Murcia, Universidad de Murcia, 119-138.

Revuelta Sañudo, M. (2008), Marcelino Menéndez Pelayo: Epistolario. Vol. 01. Junio 1868 - Marzo 1876, Alicante, Biblioteca Virtual Miguel de Cervantes, <http://www. cervantesvirtual.com/nd/ark:/59851/bmcv4176> [consultado 30/11/2019].

Rubin de Cevallos, A. (1790): Índice último de los libros prohibidos, Madrid, En la Imprenta de Don Antonio de la Sancha <http://bdh-rd.bne.es/viewer.vm?id=0000058365> [consultado 04/12/2019].

Saccenti, M. (1966), Lucrezio in Toscana: Studio su Alessandro Marchetti, Florencia, Leo S. Olschki-Editore

Traver Vera, Á. J. (2009), Lucrecio en España (Tesis Doctoral), Cáceres, Universidad de Extremadura.

Willis, J. (1972), Latin textual criticism, Urbana-Chicago-London, University of Illinois Press. 